\title{
Effect of the impact energy on the chemical homogeneity of a (Ti,Ta,Nb)(C,N) solid solution obtained via a mechanically induced self-sustaining reaction.
}

\author{
A. G. de la Obra ${ }^{1}$, F. J. Gotor ${ }^{1}$ and E. Chicardi ${ }^{2 *}$ \\ ${ }^{1}$ Instituto de Ciencia de Materiales de Sevilla (CSIC-US), Américo Vespucio 49, 41092 Sevilla, Spain. \\ ${ }^{2}$ Departamento de Ingeniería y Ciencia de los Materiales y del Transporte, Universidad de Sevilla, Avda. \\ Camino de los Descubrimientos s/n, 41092 Sevilla, Spain.
}

\begin{abstract}
.
A titanium-tantalum-niobium carbonitride solid solution, (Ti,Ta,Nb)(C,N), was synthesised in a planetary mill via a mechanochemical process that involves a mechanically induced self-sustaining reaction (MSR) from stoichiometric $\mathrm{Ti} / \mathrm{Ta} / \mathrm{Nb} / \mathrm{C}$ mixtures that are milled under a nitrogen atmosphere. The influence of the spinning rate of the planetary mill, which determines the impact energy of the milling process, on the ignition time $\left(\mathrm{t}_{\mathrm{ig}}\right)$ of the MSR process as well as the chemical homogeneity of the final product was analysed. The results indicated that the dependence of $t_{i g}$ on the spinning rate followed a potential function with a potential factor of 4.85 , implying a remarkable reduction in the milling time required to induce the self-sustaining reaction at increasing spinning rates (i.e., from $4200 \mathrm{~min}$ at $200 \mathrm{rpm}$ to $15 \mathrm{~min}$ at $800 \mathrm{rpm}$ ). However, the chemical and structural characterisation of the obtained products at ignition without any extra milling treatment indicated that a single solid solution phase was only obtained at the lowest spinning rates (i.e., less than $300 \mathrm{rpm}$ ). At increasing rates, the relative amount of the intended solid solution phase continuously decreased, and new undesirable secondary phases were formed. Despite the long milling times required for the milling experiments that were performed at the slowest spinning rates, iron contamination from the milling media was negligible due to the low intensity milling regime.
\end{abstract}

Keywords: Ceramics; chemical synthesis; gas-solid reactions; mechanochemical processing; composition fluctuations; microstructure.

* Corresponding Author: echicardi@us.es 


\section{INTRODUCTION.}

Refractory monocarbides and mononitrides from the early transition metals (IVB and $\mathrm{VB}$ groups of the periodic table: $\mathrm{Ti}, \mathrm{Zr}, \mathrm{Hf}, \mathrm{V}, \mathrm{Nb}$ and $\mathrm{Ta}$ ) possess the same $\mathrm{NaCl}$ type structure and may form complete solid solutions that lead to transition metal carbonitrides. These compounds are referred to as interstitial compounds because the $\mathrm{C}$ and/or $\mathrm{N}$ atoms occupy the octahedral interstices of the cubic close-packed metal sublattice. These compounds are non-stoichiometric and exist over a wide compositional range $[1,2]$. Due to the outstanding combination of properties, such as high melting temperature, high chemical stability, high hardness, good wear resistance and good thermal and electrical conductivities, these compounds are appropriate for the development of materials with a wide range of technical applications in various fields, such as in the automotive, aerospace, industrial machinery and equipment, armour, nuclear, semiconductor, optical and machining industries [3].

Carbides and, to a lesser extent, carbonitrides, are easily wetted by molten metals, and combine with a metal binder that is primarily based on $\mathrm{Ni}$ or Co [4-6] to produce ceramic-metal composites or cermets, resulting in improved toughness, thermal shock resistance and mechanical strength $[7,8]$. Ti(C,N)-based cermets have found interesting applications in the metal cutting industry for a variety of machining operations (e.g., as inserts in tools for metals, stones or other hard materials, wire-drawing dies, mining tools for cutting coals and various ores and rocks and drilling tools for oil) [9-12] .The use of cermets allows for excellent finishing surfaces and narrow manufacturing tolerances in milling, cutting and roughing operations of carbon steel, superalloys and other materials that are difficult to machine with conventional cutting tools [13].

Although $\operatorname{Ti}(\mathrm{C}, \mathrm{N})$ is the main ceramic component in cermets, other transition metal carbides have also been introduced as secondary hard phases to modify and/or 
modulate the final properties. For example, $\mathrm{TaC}$ and $\mathrm{NbC}$ are added to improve the high temperature hardness, thermal shock resistance and oxidation resistance $[11,14,15]$, and $\mathrm{VC}$ and $\mathrm{Mo}_{2} \mathrm{C}$ are used to inhibit ceramic grain growth and improve the sinterability [16, 17]. During the liquid phase sintering step, which is necessary to consolidate the cermet, a characteristic microstructure called a core-rim is developed in the ceramic particles. The core corresponds to the original carbonitride particles, and the rim is a newly formed phase, which is a carbonitride solid solution containing Ti and other transition metals introduced as single carbides, resulting from a dissolutionreprecipitation process [18]. Although this core-rim microstructure, especially the rim phase, is responsible for the good mechanical behaviour of cermets, the possible presence of residual stresses at the interface between the core and the rim may be detrimental to the toughness because these stresses may induce crack propagation and premature failure during service [19].

To obtain superior strength characteristics, Rudy [20] proposed the use of carbonitride solid solutions rather than mixtures of different binary carbides, nitrides or carbonitrides as the starting ceramic material. The composition of these solid solutions, which contain $\mathrm{Ti}$ and group VI metals, was designed such that during sintering, a spinodal decomposition reaction occurs in the carbonitride phase, which combined with the diffusional reactions occurring in the liquid binder during sintering, resulted in a unique microstructure in which the ceramic particles exhibit coherent and low stress interfaces between phases with similar lattice parameters. Subsequently, other authors have proposed that the ability to achieve the toughness values of cemented carbides will only be possible by developing so-called complete solid solution cermets (CSCs), which are characterised by ceramic particles composed of only a single carbonitride solid solution phase (without internal interfaces) [21-24]. These cermets would also permit 
facile tailoring of the properties by precisely controlling the chemical composition of the carbonitride solid solution. Nevertheless, the most important problem for manufacturing this type of cermet requires appropriate synthesis of the carbonitride solid solutions.

A common synthetic route for obtaining transition metal carbides, nitrides and carbonitrides involves the carbothermal reduction of transition metal oxides with activated carbon as the reducing agent in an inert atmosphere that can also contain $\mathrm{H}_{2}$ and/or $\mathrm{N}_{2}$ [25]. Other methods using different precursors from both the corresponding transition metal (e.g., chlorides and hydrides) and $\mathrm{C}$ and/or N (e.g., ammonia, hydrazine and carbon-rich organic media) have also been developed [26]. However, all these methods are energy intensive and may require milling for particle size reduction. To improve morphological control and purity, alternative routes, such as vapour deposition methods (CVD and PVD) [27-29], plasma synthesis [30, 31] and the sol-gel method [32, 33], have been developed. Recently, the self-propagating high-temperature synthesis (SHS) method [34-36] has been implemented for this goal. Although all these methods can be potentially applied to synthesise solid solutions, few studies have focused on reliable syntheses, and only restricted compositions have been evaluated.

Recently, the mechanically induced self-sustaining reaction process (MSR) has been employed to obtain a wide range of complex carbonitrides that contain two different transition metals in an affordable and simple fashion [37-39], and different CSCs have been developed using this methodology [8, 40-43]. MSR processes [44] are comparable to SHS and may occur during milling extremely exothermic powder mixtures. After a critical milling time, which is referred to as the ignition time $\left(t_{\mathrm{ig}}\right)$, a self-sustaining reaction is initiated and propagates through the powder charge, transforming the reactants into products. Therefore, this reactive milling method uses 
the strong exothermic character of the carbonitride formation from the elements to obtain carbonitride solid solutions with acceptable control of the stoichiometry simply by fixing the starting metal-to-carbon atomic ratio. However, unreacted transition metals and/or secondary phases are occasionally detected after the MSR synthesis of the carbonitride solid solutions [37, 45].

The success of an MSR process depends on the right choice of the reactant mixture as well as the employed milling conditions [46]. In planetary mills, the spinning rate (i.e., the rotational speed of the planetary mill) is one of the most important milling intensity parameters since it determines both the impact energy (i.e., the kinetic energy transferred at the collision event between the balls and the inner walls of the vials entrapping the reactants) and the impact frequency. In this study, the influence of the spinning rate on the chemical homogeneity of a carbonitride solid solution containing three different transition metals ( $\mathrm{Ti}, \mathrm{Nb}$ and $\mathrm{Ta}$ ) obtained by MSR was analysed. The final goal of this study was to synthesise highly homogeneous solid solutions, which is important for the successful manufacturing of CSCs.

\section{EXPERIMENTAL PROCEDURE.}

Titanium powder (99\% purity, <325 mesh, Strem Chemicals), tantalum powder (99.6\% purity, <325 mesh, Alfa-Aesar), niobium power (99.8\% in purity, <60 mesh, Sigma-Aldrich) and graphite powder ( $<270 \mathrm{mesh}, \mathrm{Fe}<0.4 \%$, Merck) were used to synthesise a titanium-tantalum-niobium carbonitride solid solution with a nominal composition of $\left(\mathrm{Ti}_{0.8} \mathrm{Ta}_{0.1} \mathrm{Nb}_{0.1}\right)\left(\mathrm{C}_{0.5} \mathrm{~N}_{0.5}\right)$ via MSR. Five grams of the stoichiometric $\mathrm{Ti} / \mathrm{Ta} / \mathrm{Nb} / \mathrm{C}$ mixture were milled under 6 bar of high-purity nitrogen gas $\left(\mathrm{H}_{2} \mathrm{O}\right.$ and $\mathrm{O}_{2}$ <63 ppm, Linde) in a modified planetary ball mill (Planetary Micro Mill 
PULVERISETTE 7 (P7) classic line Fritsch) at different milling spinning rates that ranged from 200 to $800 \mathrm{rpm}$. The ratio between the rotational speed of the supporting disc and the rotational speed of the vial in the opposite direction was fixed at -1 in the P7 mill. The milling media consisted of a $45 \mathrm{ml}$ tempered steel vial (67Rc) and seven hardened stainless steel balls $(\mathrm{d}=15 \mathrm{~mm}, \mathrm{~m}=13.7 \mathrm{~g})$, resulting in a ball-to-powder ratio (BPR) of 19 . It is important to note that the $\mathrm{Ti} / \mathrm{Ta} / \mathrm{Nb} / \mathrm{C}$ mixture was introduced into the vial without any prior premixing step, which is performed in typical ball milling experiments on the laboratory scale.

The modified P7 device allowed for operation at a constant gas pressure and detection of self-sustaining reactions. During milling, a vial with a special lid was continuously connected to the gas cylinder by a rotating union (model 1005-163-038, Deublin) and a flexible polyamide tube, and the gas pressure was continuously monitored with a pressure transducer (AKS Danfoss) that was connected to a data paperless recorder (Ecograph T RSG30, Endress+Hauser). When the ignition occurred, the increase in temperature due to the exothermic reaction produced an instantaneous increase in the total pressure and the appearance of a sharp peak in the pressure-time record. Based on this information, $\mathrm{t}_{\mathrm{ig}}$ for the process was determined. It is important to note that the milling process was stopped exactly at ignition when the pressure spike occurred because an alarm in the paperless recorder activated an internal ON/OFF switch that halted the action of the planetary mill, which allowed the chemical and microstructural characterisation of the product obtained immediately after ignition without any post-ignition milling treatment.

The X-ray diffraction (XRD) patterns of the as-milled powder mixtures were collected on a PANalytical X'Pert Pro diffractometer in reflection mode using a BragBrentano $\theta / \theta$ configuration, $\mathrm{Cu} \mathrm{K}_{\alpha}$ radiation $\left(40 \mathrm{kV}, 40 \mathrm{~mA}\right.$ ), a secondary $\mathrm{K}_{\beta}$ filter and 
an $X^{\prime}$ Celerator detector. The diffraction patterns were scanned from $2 \theta=20^{\circ}$ to $2 \theta=$ $140^{\circ}$ at a step of $0.02^{\circ}$ and a counting time of 275 s/step. Silicon powder (Standard Reference Material 640c, NIST) was used for calibration of the diffraction line positions. The phases detected as well as their structures were elucidated from the entire set of peaks in the XRD diagrams using the Dicvol06 software and the PDF-4+ database from the International Centre for Diffraction Data (ICDD). The XRD patterns were also refined by the Rietveld method using the Fullprof Software. The refined parameters included the background, scale factor, lattice parameters, specimen position displacement, atomic positions and strain/size factors. This refinement allowed for the determination of the weight percentage of each phase present in the different samples.

The scanning electron microscopy (SEM) images were obtained on a Hitachi S4800 SEM-Field Emission Gun microscope in secondary electron mode. The Ti, Ta, Nb and $\mathrm{Fe}$ contents (the presence of Fe resulted from milling media contamination) were measured by energy dispersive X-ray spectrometry (XEDS) in a semi-quantitative mode with a detector coupled to the SEM microscope. The reported values (mean value and standard deviation) were the result of at least 20 measurements.

Finally, the overall carbon and nitrogen contents in the as-milled powders were determined by elemental analysis (Thermo Finnigan elemental analyser, mod. Flash EA1112 CHNS-O).

\section{RESULTS AND DISCUSSION.}

Table 1 summarises the $t_{\mathrm{ig}}$ values observed for the different experiments performed at various spinning rates. The samples obtained at ignition were labelled RPM200, RPM300, RPM400, RPM600 and RPM800. A drastic increase in $t_{\mathrm{ig}}$ was observed when the spinning rate was decreased from 15 min for the RPM800 sample to 
4200 min (280 times longer) for RPM200. The dependence of $t_{i g}$ on the spinning rate was fit to a potential function with a general expression $y=a \cdot x^{-b}$, as shown in figure 1 . As previously mentioned, when the spinning rate increased, both the impact energy and impact frequency also increased, which resulted in a substantial decrease in the time required to induce ignition.

If we assumed that impacts between the balls and the vial are the events that cause the energy to be transferred to a powder mixture, predictive models based on kinematic equations [47] have indicated that the total power transmitted during a milling process varies as the third order of the spinning rate. However, because a direct relationship between $1 / t_{\text {ig }}$ and the power transferred from the mill has been proposed [48], the results in figure 1 suggest a higher potential factor for the dependence between the total power and the spinning rate (i.e., 4.85 rather than 3). This discrepancy is not surprising because several studies $[49,50]$ based on in situ observations have revealed that the real ball trajectories significantly differ from those calculated using the kinematic equations, especially when multiple balls are used. Moreover, other factors, such as the existence of shear forces (not only impact forces) or the elastic properties of the impact media, may also contribute to this disagreement [51].

Considering the time savings for inducing the MSR process using an increased spinning rate, which may also reduce contamination from the milling media (one of the main problems attributed to mechanochemical processes), the best option may be to increase the spinning rate of the planetary mill as much as possible. However, the XRD patterns of the powders after ignition (figure 2) indicated that a decrease in the homogeneity of the product was observed as the spinning rate increased. The anticipated complete solid solution phase was achieved only at the lowest spinning rates (i.e., 200 and $300 \mathrm{rpm}$ ). The XRD patterns of the RPM200 and RPM300 samples 
revealed the formation of a single cubic phase with a space group symmetry of $F m-3 m$, which was indexed as a titanium-tantalum-niobium carbonitride $((\mathrm{Ti}, \mathrm{Ta}, \mathrm{Nb})(\mathrm{C}, \mathrm{N}))$ by comparison with the reference diffraction patterns of TiN (38-1420), TiC (32-1383), TaC (35-0801), TaN, (49-1283), NbC (38-1364) and NbN (38-1155), as performed by authors in previous studies [23, 40, 41].

When the spinning rate was progressively increased, the XRD patterns of the samples (figure 2) evolved into a pattern corresponding to a multiphasic product, where the relative amount of the major $(\mathrm{Ti}, \mathrm{Ta}, \mathrm{Nb})(\mathrm{C}, \mathrm{N})$ phase continuously decreased. In addition, new secondary phases appeared, and some of these phases had similar symmetries and structures but different lattice parameters. The results in figure 2 indicate that the quantity of undesirable phases was important for samples obtained at the highest spinning rates (i.e., RPM600 and RPM800 samples). The new diffraction peaks observed for the RPM400, RPM600 and RPM800 samples, which were located at lower $2 \theta$ values with respect to the major phase, were consistent with a cubic phase with the same space group symmetry, which was assigned to a new carbonitride phase that most likely possessed a composition highly rich in $\mathrm{Ta}$ and/or $\mathrm{Nb}$. Based on the diffraction peak positions for $\mathrm{TaC}$ (35-0801), TaN, (49-1283), NbC (38-1364) and NbN (38-1155), the formation of $\mathrm{Ta}(\mathrm{C}, \mathrm{N})$ and $\mathrm{Nb}(\mathrm{C}, \mathrm{N})$ or even a $(\mathrm{Ta}, \mathrm{Nb})(\mathrm{C}, \mathrm{N})$ solid solution was likely.

In addition, other diffraction peaks corresponding to unreacted $\mathrm{Ti}$ (hexagonal structure and space group symmetry $\mathrm{P} 63 / \mathrm{mmc}$ ), Ta and $\mathrm{Nb}$ or the Ta-Nb alloy (both metals have practically identical cubic structure, space group symmetry $\operatorname{Im} 3 m$ ), were detected at $400 \mathrm{rpm}$ and higher spinning rates. The presence of these metal phases was confirmed by comparison to the XRD reference patterns for Ti (44-1294), Ta (4-0788) 
and $\mathrm{Nb}$ (35-0789). This evidence indicates that the MSR process was unable to achieve full conversion immediately after ignition.

Moreover, in RPM400 and especially the RPM600 and RPM800 samples, extra XRD peaks were also observed at slightly higher $2 \theta$ values with respect to the major phase peaks. The position of these XRD peaks were consistent with a new cubic phase $(F m-3 m)$ that corresponded to another $(\mathrm{Ti}, \mathrm{Ta}, \mathrm{Nb})(\mathrm{C}, \mathrm{N})$ solid solution. However, in this case, the solid solution possessed a stoichiometry richer in Ti. For the previous secondary carbonitride solid solution, the amount of this new phase increased with the spinning rate.

To quantify the amount of each phase at the studied spinning rates, a Rietveld analysis was carried out for the XRD patterns collected for the five powder samples. The five different phases considered in the refinement were those previously detected and indexed by XRD (i.e., the major $(\mathrm{Ti}, \mathrm{Ta}, \mathrm{Nb})(\mathrm{C}, \mathrm{N})$ solid solution denoted as $(\mathrm{Ti}, \mathrm{Ta}, \mathrm{Nb})(\mathrm{C}, \mathrm{N}) \_\mathrm{A}$, the minor $(\mathrm{Ti}, \mathrm{Ta}, \mathrm{Nb})(\mathrm{C}, \mathrm{N})$ solid solution richer in $\mathrm{Ti}$ denoted as $(\mathrm{Ti}, \mathrm{Ta}, \mathrm{Nb})(\mathrm{C}, \mathrm{N}) \_\mathrm{B}$, the $(\mathrm{Ta}, \mathrm{Nb})(\mathrm{C}, \mathrm{N})$ solid solution, the Ta-Nb alloy and elemental $\left.\mathrm{Ti}\right)$. The stoichiometry of the different carbonitride solid solutions was initially derived from the semi-quantitative $\mathrm{Ti}$, Ta and $\mathrm{Nb}$ results obtained by XEDS-SEM, and the $\mathrm{C}$ and $\mathrm{N}$ contents determined by elemental analysis as discussed below. These compositions were used as input data for the Rietveld analysis and were refined without any notable change. Therefore, the values presented in table 5 (discussed below) are a good estimate of the stoichiometry of the different phases.

The weight percentage of each phase present in the powder mixtures after the MSR reaction determined by the Rietveld analysis is shown in table 2 . The goodness of the fitting parameters $\left(\mathrm{R}_{\exp }\right.$ and $\left.\mathrm{R}_{\mathrm{wp}}\right)$, which is also shown in table 2, demonstrated the 
optimal fitting of the XRD patterns. For example, the Rietveld refinement results for the RPM800 sample is shown in figure 3, and excellent fit between the observed and calculated patterns was obtained. The percentage of phases was also plotted as a function of the spinning rate, as shown in figure 4. The quantification results confirmed that the complete solid solution phase was practically achieved by MSR only at low spinning rate (RPM200 and RPM300). By increasing the spinning rate, increasing amounts of undesirable phases (unreacted and secondary phases) were gradually produced, and only approximately $50 \mathrm{wt} \%$ of the intended phase was obtained at the highest spinning rates.

Using the Rietveld refinement method, the lattice parameters of the different phases were also determined (table 3 ). The values calculated for unreacted $\mathrm{Ti}$, Ta and $\mathrm{Nb}$ (or Ta-Nb alloy) in the RPM400, RPM600 and RPM800 samples were close to the theoretical lattice parameters in the XRD reference patterns for $\mathrm{Ti}(\mathrm{a}=\mathrm{b}=2.9505 \AA$ and $\mathrm{c}=4.6826 \AA), \mathrm{Nb}(\mathrm{a}=3.3033 \AA)$ and $\mathrm{Ta}(\mathrm{a}=3.3058 \AA)$. Moreover, the lattice parameter for the $(\mathrm{Ta}, \mathrm{Nb})(\mathrm{C}, \mathrm{N})$ phase was intermediate between the corresponding values for the TaC-TaN and $\mathrm{NbC}-\mathrm{NbN}$ pairs, which is in agreement with the previous assignment. The lattice parameters for both the $(\mathrm{Ti}, \mathrm{Ta}, \mathrm{Nb})(\mathrm{C}, \mathrm{N}) \_\mathrm{A}$ and $(\mathrm{Ti}, \mathrm{Ta}, \mathrm{Nb})(\mathrm{C}, \mathrm{N}) \_\mathrm{B}$ phases were also in agreement with the assumed stoichiometry (i.e., $(\mathrm{Ti}, \mathrm{Ta}, \mathrm{Nb})(\mathrm{C}, \mathrm{N}) \_\mathrm{A}$ close to the starting nominal composition and $(\mathrm{Ti}, \mathrm{Ta}, \mathrm{Nb})(\mathrm{C}, \mathrm{N}) \_\mathrm{B}$ with a higher Ti content). It is important to note that the lattice parameters for the different phases in the five samples were nearly constant, and only very small differences were observed, suggesting similar chemical compositions in all cases. Therefore, the differences between samples were primarily due to the relative amount of the coexisting phases rather than their stoichiometries. The crystalline domain size (D) and the microstrain content (e) were also determined for the different carbonitride solid 
solution phases (table 4). All the phases had a nanometric character as expected by the large broadening of the XRD peaks in figure 2. Similar D and e values were found for all of them irrespective of the spinning rate used.

To gain additional insight into the chemical composition and morphology of the different phases detected by XRD after the MSR process, the samples were characterised by SEM and XEDS. The SEM images in figure 5 show the formation of particles with irregular morphology and aggregates with larger sizes as the spinning rate increased, from approximately $10-15 \mu \mathrm{m}$ in size for RPM200 to larger than $50 \mu \mathrm{m}$ for RPM800. The size of particles observed by SEM contrasts with the nanometric character deduced from the XRD measurements. This is not contradictory since the crystalline domain size obtained by XRD is different from the particle size observed by SEM. It has been demonstrated in previous studies on similar systems obtained by MSR $[37,45]$ that particles (as observed by SEM) are in fact constituted by multiple misoriented nanodomains, which are in a size range of $20-40 \mathrm{~nm}$, approximately.

In the SEM micrographs, large particles with a sintered aspect (marked for example with a dotted square in figure 5 for the RPM800 sample) and evidence of the formation of a transient liquid phase were observed. This particular morphology was also observed in the other powder mixtures, as shown in the SEM images in figure 6 at higher magnification. In this case, ceramic particles sintered by thin regions reminiscent of the existence of a molten metal were observed. The presence of these large particles and aggregates after the MSR process was due to the large heat release from the exothermic reaction that locally produced very high temperatures that could potentially induce melting of the $\mathrm{Ti}$, which has the lowest melting point. In the current study, milling was precisely halted at ignition, and therefore, the crushing and reduction of the particle size due to extra post-ignition milling was avoided. The appearance of a liquid 
phase at ignition in the MSR processes was previously observed for the Ti-C similar system [52].

The presence of smaller particles as the spinning rate decreased may be due to the lower maximum temperature reached during the MSR process. However, at high spinning rates, the presence of unreacted phases suggests less heat release, which appears to be contradictory. It is important to note that $t_{\mathrm{ig}}$ increased substantially as the spinning rate decreased (table 1), and during this milling time prior to ignition, comminution, mixing and defect formation occurred. Therefore, the quality of the reactant mixture that ignites (i.e., smaller particle size and better mixing) should be improved for RPM200 compared to RPM800. This improved quality may be responsible for both the smaller particle size of the product and the higher conversion observed when the spinning rate was decreased.

Interestingly, in the RPM600 and RPM800 samples in figure 6, the different contrast in the different regions of the ceramic particles may indicate a different metal content. A brighter contrast may be related to a higher content of heavy elements (Ta and $\mathrm{Nb}$ ), and a darker contrast may be related to a higher content of Ti. This effect was not observed in the other samples obtained at lower spinning rates, which is consistent with the XRD patterns that were previously discussed.

XEDS-SEM mappings were carried out on some particles from the powder mixtures after the MSR process (figure 7). A homogeneous distribution of the three transition metals was observed in the RPM200 and RPM300 samples (XEDS-SEM mapping for RPM200 similar to RPM300 was not shown). In RPM400, some areas with slightly higher colour intensities were observed, indicating that the spatial distribution of the elements in the sample begins to become less homogeneous. In the 
RPM600 XEDS-SEM mapping, some areas with a high content of Ta and/or $\mathrm{Nb}$ and almost no Ti were visible, although the presence of the three metals was detected in other areas. It is important to note that it was impossible to discriminate the carbonitride solid solution phases with similar stoichiometries by XEDS-SEM mapping. Finally, in the RPM800 sample, larger areas enriched in $\mathrm{Ta}$ and $\mathrm{Nb}$ were observed, which is in agreement with the XRD results.

To quantify the transition metal composition of different carbonitride solid solutions observed by XRD, XEDS-SEM point analysis was also carried out, and the results are shown in table 5. First, it is important to note that the Fe contamination was always less than 1 wt.\%. This low Fe content revealed that the long milling times required for the milling experiments performed at slower spinning rates did not induce additional contamination, which is most likely due to the low intensity milling regime that was used.

In all the samples, a $(\mathrm{Ti}, \mathrm{Ta}, \mathrm{Nb})(\mathrm{C}, \mathrm{N})$ solid solution with a $\mathrm{Ti} / \mathrm{Ta} / \mathrm{Nb}$ atomic ratio close to the starting nominal composition (80/10/10), especially for the RPM200 and RPM300 samples, was observed and corresponded to the intended carbonitride phase that was previously denoted as $(\mathrm{Ti}, \mathrm{Ta}, \mathrm{Nb})(\mathrm{C}, \mathrm{N}) \_\mathrm{A}$ (the major phase). A slight enrichment in Ti was observed in this phase as the spinning rate increased, which is in agreement with the formation of the previously mentioned $(\mathrm{Ta}, \mathrm{Nb})(\mathrm{C}, \mathrm{N})$ solid solution. In the RPM200 and RPM300 samples, only the $(\mathrm{Ti}, \mathrm{Ta}, \mathrm{Nb})(\mathrm{C}, \mathrm{N}) \_\mathrm{A}$ phase was detected. However, for the remaining samples, a second $(\mathrm{Ti}, \mathrm{Ta}, \mathrm{Nb})(\mathrm{C}, \mathrm{N})$ solid solution with a stoichiometry richer in Ti was also detected. This solid solution was previously labelled $(\mathrm{Ti}, \mathrm{Ta}, \mathrm{Nb})(\mathrm{C}, \mathrm{N}) \_$B. A richer Ti composition was determined for this phase as the spinning rate increased, which is in agreement with an increasing amount of $(\mathrm{Ta}, \mathrm{Nb})(\mathrm{C}, \mathrm{N})$. Finally, for the RPM600 and RPM800 samples, the existence of a third 
carbonitride phase with a high content of $\mathrm{Ta}$ and/or $\mathrm{Nb}$, which corresponded to $(\mathrm{Ta}, \mathrm{Nb})(\mathrm{C}, \mathrm{N})$, was also confirmed by XEDS-SEM point analysis.

$\mathrm{C}$ and $\mathrm{N}$ elemental analyses were also performed (table 5) to determine the complete stoichiometry of the carbonitride phases that were formed by MSR. The presence of nitrogen in all the samples provided new evidence for the formation of carbonitride phases during the MSR process. The $\mathrm{C}$ content in these phases was identical because the amount of $\mathrm{C}$ introduced as one of the components of the starting reactant mixture always remained the same. This content was in close agreement with the $(\mathrm{Ti}+\mathrm{Ta}+\mathrm{Nb}) / \mathrm{C}$ atomic ratio of 0.5 , which supported the accuracy of the measurement. The presence of free (unreacted) carbon after the synthesis by MSR of different transition metal carbides and carbonitrides has never been observed after deep characterization performed by XRD, SEM, TEM, HR-TEM and/or EELS [40, 41], even when an extra carbon amount was added [22].

However, the obtained $\mathrm{N}$ content indicated a $\mathrm{C} / \mathrm{N}$ atomic ratio that was higher than 1, which indicated the formation of a nitrogen-deficient carbonitride phase. Because a single phase was formed in the RPM200 and RPM300 samples, the carbonitride stoichiometry of both samples was approximately $\mathrm{Ti}_{0.8} \mathrm{Ta}_{0.1} \mathrm{Nb}_{0.1} \mathrm{C}_{0.5} \mathrm{~N}_{0.3}$ based on the XEDS-SEM and $\mathrm{C}$ and $\mathrm{N}$ analyses. The slightly lower $\mathrm{N}$ content that was observed for the remaining samples was primarily due to the presence of unreacted metals after the MSR process. The results also suggest a similar $\mathrm{C} / \mathrm{N}$ atomic ratio for the secondary carbonitride phases that were formed at increasing spinning rates. The observed nitrogen deficiency was in agreement with previous studies of the synthesis of transition metal carbonitrides by $\operatorname{MSR}[8,37]$, wherein the $\mathrm{C} / \mathrm{N}$ ratios were slightly higher than the nominal starting stoichiometry. As mentioned in the introduction, 
carbides, nitrides and carbonitrides of groups IV and $\mathrm{V}$ transition metals are nonstoichiometric compounds with extended homogeneity intervals [53].

Although in terms of milling efficiency, the increase in the spinning rate may seem beneficial (time savings), this increase can produce detrimental effects because makes obtaining a single phase difficult. It has been established that as the conversion of the MSR reaction is not $100 \%$ complete immediately after the self-sustaining process, continued milling is required to obtain fully reacted products with a uniform microstructure and properties [44]. Therefore, a post-ignition milling treatment is typically performed, and full conversion is determined by XRD examination of the milling products. However, the post-ignition milling treatment can affect the microstructure of the material because the particle and/or crystallite size is reduced and residual stresses are introduced that decrease the XRD peak intensity (lower signal-tonoisy ratio), which is accompanied by a non-negligible peak broadening. These changes in the XRD pattern may mask the detection of unwanted phases. To illustrate this effect, the XRD patterns of the RPM600 sample (immediately after ignition) and after being milled for $1 \mathrm{~h}$ are compared in figure 8 . If this sample was inspected only after the $1 \mathrm{~h}$ post-ignition milling treatment, the erroneous conclusion that the desired phase was correctly obtained would have been obtained.

\section{CONCLUSIONS.}

A titanium-tantalum-niobium carbonitride single phase $((\mathrm{Ti}, \mathrm{Ta}, \mathrm{Nb})(\mathrm{C}, \mathrm{N}))$ was synthesised via the MSR process. The introduction of three transition metals in the composition as a quinary system is a new advance in the development of this type of material by MSR. The ignition time of the MSR process was shortened when the 
spinning rate of the planetary mill was increased. However, a multiphasic product with an increasing amount of unwanted secondary phases was obtained. Complete conversion as well as the formation of a practically single phase was only possible at the lowest spinning rates (i.e., less than $300 \mathrm{rpm}$ ), which implies that long milling times are needed to achieve a perfect mixing state for the reactants and optimal activation facilitate the propagation of the reaction front. Despite the long milling times, contamination from the milling media was negligible due to the low intensity milling regime.

\section{Acknowledgements.}

This study was supported by the Spanish Government under grant MAT201452407-R, which was financed in part by the European Regional Development Fund.

\section{References.}

[1] W. Lengauer, Transition Metal Carbides, Nitrides, and Carbonitrides, Wiley-VCH., 2008.

[2] A.V. Linde, V.V. Grachev, R.M. Marin-Ayral, Self-propagating high-temperature synthesis of cubic niobium nitride under high pressures of nitrogen, Chemical Engineering Journal, 155 (2009) 542-547.

[3] H.O. Pierson, 16 - Applications of Refractory Carbides and Nitrides, in: Handbook of Refractory Carbides and Nitrides, William Andrew Publishing, Westwood, NJ, 1996, pp. 309-326.

[4] A. Rajabi, M.J. Ghazali, J. Syarif, A.R. Daud, Development and application of tool wear: A review of the characterization of TiC-based cermets with different binders, Chemical Engineering Journal, 255 (2014) 445-452.

[5] Z. Shi, D. Yin, D. Zhang, X. Liu, Characterisation of Ti(C, N)-based cermets with various nitrogen contents studied by EBSD/SEM and TEM, Journal of Alloys and Compounds, 695 (2017) 2857-2864.

[6] Q. Xu, X. Ai, J. Zhao, F. Gong, J. Pang, Y. Wang, Effects of metal binder on the microstructure and mechanical properties of $\mathrm{Ti}(\mathrm{C}, \mathrm{N})$-based cermets, Journal of Alloys and Compounds, 644 (2015) 663-672.

[7] D.J. Waldford, Stender, M., Liu, S., Norgan, D., Alternative Binder Carbide Tools for Machining Superalloys, in: Proceedings of the International Conference on Manufacturing Science and Engineering, 2008. 
[8] J.M. Córdoba, E. Chicardi, F.J. Gotor, Development of multicomponent-multiphase materials based on $(\mathrm{Ti}, \mathrm{Ta}, \mathrm{Nb}) \mathrm{CxN1}-\mathrm{x}$ carbonitride solid solutions, Chemical Engineering Journal, 192 (2012) 58-66.

[9] H. Pastor, Titanium-carbonitride-based hard alloys for cutting tools, Materials

Science and Engineering, 105-106 (1988) 401-409.

[10] S.-R.S. Liu, Compositions of Hardmetal Materials with Novel Binders, in, United States Genius Metal, Inc., Arcadia, CA, US, 2008.

[11] P. Ettmayer, H. Kolaska, W. Lengauer, K. Dreyer, Ti(C,N) Cermets - Metallurgy and Properties, International Journal of Refractory Metals and Hard Materials, 13 (1995) 343.

[12] Z.A.R. Munir, M. Eslamloo-Grami, Synthesis of transition metal carbonitrides, in, United State Patent, 1994.

[13] H. Pastor, Present status and development of tool materials: part 1 cutting tools, International Journal of Refractory Metals and Hard Materials, 6 (1987) 196-209.

[14] E. Chicardi, J.M. Córdoba, F.J. Gotor, High temperature oxidation resistance of (Ti,Ta)(C,N)-based cermets, Corrosion Science, 102 (2016) 125-136.

[15] E. Chicardi, F.J. Gotor, J.M. Cordoba, Enhanced oxidation resistance of Ti(C,N)based cermets containing Ta, Corrosion Science, 84 (2014) 11-20.

[16] H. Yu, W.N. Li, X.Q. Jiang, P.H. Jiao, Effect of VC, TaC and $\mathrm{NbC}$ additions on microstructure and properties of ultrafine WC-10\%Co cemented carbides, in, Kunming, 2013, pp. 281-286.

[17] J. Xiong, Z. Guo, B. Shen, D. Cao, The effect of WC, Mo2C, TaC content on the microstructure and properties of ultra-fine TiC0.7N0.3 cermet, Materials \& Design, 28 (2007) 1689-1694.

[18] P. Li, J. Ye, Y. Liu, D. Yang, H. Yu, Study on the formation of core-rim structure in $\mathrm{Ti}(\mathrm{CN})$-based cermets, International Journal of Refractory Metals \& Hard Materials, 35 (2012) 27-31.

[19] Y. Liu, Y. Jin, H. Yu, J. Ye, Ultrafine (Ti,M)(C,N)-based cermets with optimal mechanical properties, International Journal of Refractory Metals and Hard Materials, 29 (2011) 104-107.

[20] E. Rudy, Spinodal carbonitride alloys for tool and wear applications, in, Google Patents, 1976.

[21] J.W. Kim, S.Y. Ahn, S. Kang, Effect of the complete solid-solution phase on the microstructure of $\mathrm{Ti}(\mathrm{CN})$-based cermet, International Journal of Refractory Metals \& Hard Materials, 27 (2009) 224-228.

[22] E. Chicardi, Y. Torres, M.J. Sayagues, V. Medri, C. Melandri, J.M. Cordoba, F.J. Gotor, Toughening of complete solid solution cermets by graphite addition, Chemical Engineering Journal, 267 (2015) 297-305.

[23] E. Chicardi, Y. Torres, J.M. Córdoba, M.J. Sayagués, J.A. Rodríguez, F.J. Gotor, Effect of sintering time on the microstructure and mechanical properties of $(\mathrm{Ti}, \mathrm{Ta})(\mathrm{C}, \mathrm{N})$-based cermets, International Journal of Refractory Metals and Hard Materials, (2013).

[24] A.G. de la Obra, M.A. Avilés, Y. Torres, E. Chicardi, F.J. Gotor, A new family of cermets: Chemically complex but microstructurally simple, International Journal of Refractory Metals and Hard Materials.

[25] H.O. Pearson, Handbook of refractory carbides and nitrides, Noyes publications, Westwood, New Jersey, USA, 1996.

[26] L.S. Millberg, The synthesis of ceramic powders., Journal of Metals, 39 (1987) 913. 
[27] H.O. Pearson, Handbook of chemical vapor deposition (CVD), Second edition ed., Park Ridge, New Jersey, U.S.A, 1999.

[28] Y. Yuan, J. Pan, The morphology and growth mechanism of TiC whisker prepared by chemical vapour deposition, Journal of Materials Science, 33 (1998) 5773-5780.

[29] C.E. Bauer, W.A. Bryant, CVD grown transition metal carbide, nitride and carbonitride whiskers|with removal of residual nickel catalyst by volatilisation as chloride, in, Kennametal Inc; Bauer C E.

[30] J.-H. Seo, B.-G. Hong, Thermal plasma synthesis of nano sized powders., Nuclear Engineering and Technology, 44 (2012) 9-20.

[31] R.L. Stephens, Radio frequency plasma synthesis of ultrafine titanium carbide powders, in, The University of Auckland, Auckland, 1994.

[32] H. Zhang, F. Li, Q. Jia, G. Ye, Preparation of titanium carbide powders by sol-gel and microwave carbothermal reduction methods at low temperature, Journal of Sol-Gel Science and Technology, 46 (2008) 217-222.

[33] M. Dolle, D. Gosset, C. Bogicevic, F. Karolak, D. Simeone, G. Baldinozzi, Synthesis of nanosized zirconium carbide by a sol-gel route, Journal of the European Ceramic Society, 27 (2007) 2061-2067.

[34] Z.A. Munir, U. Anselmi-Tamburini, Self-propagating exothermic reactions: The synthesis of high-temperature materials by combustion, Materials Science Reports, 3 (1989) 277-365.

[35] B. Zou, J. Xu, Y. Wang, S. Zhao, X. Fan, Y. Hui, X. Zhou, W. Huang, X. Cai, S. Tao, H. Ma, X. Cao, Self-propagating high-temperature synthesis of TiC-TiB2-based Co cermets from a Co-Ti-B4C system and fabrication of coatings using the cermet powders, Chemical Engineering Journal, 233 (2013) 138-148.

[36] Y.X. Li, J.D. Hu, H.Y. Wang, Z.X. Guo, Study of TiC/Ni3Al composites by laser ignited self-propagating high-temperature synthesis (LISHS), Chemical Engineering Journal, 140 (2008) 621-625.

[37] J.M. Córdoba, M.A. Avilés, M.J. Sayagués, M.D. Alcalá, F.J. Gotor, Synthesis of complex carbonitride powders TiyMT1-yCxN1-x (MT:Zr,V,Ta,Hf) via a mechanically induced self-sustaining reaction, Journal of Alloys and Compounds, 482 (2009) 349355.

[38] J.M. Cordoba, E. Chicardi, R. Poyato, F.J. Gotor, V. Medri, S. Guicciardi, C. Melandri, Spark plasma sintering of TixTa1-xC0.5N0.5-based cermets: Effects of processing conditions on chemistry, microstructure and mechanical properties, Chemical Engineering Journal, 230 (2013) 558-566.

[39] A. Borrell, M. Dolores Salvador, V. Garcia-Rocha, A. Fernandez, E. Chicardi, F.J. Gotor, Spark plasma sintering of TiyNb1-yCxN1-x monolithic ceramics obtained by mechanically induced self-sustaining reaction, Materials Science and Engineering aStructural Materials Properties Microstructure and Processing, 543 (2012) 173-179. [40] E. Chicardi, J.M. Córdoba, M.J. Sayagués, F.J. Gotor, Absence of the core-rim microstructure in TixTa1-XCyN1-y-based cermets developed from a pre-sintered carbonitride master alloy, International Journal of Refractory Metals and Hard Materials, 33 (2012) 38-43.

[41] E. Chicardi, J.M. Córdoba, M.J. Sayagués, F.J. Gotor, Inverse core-rim microstructure in $(\mathrm{Ti}, \mathrm{Ta})(\mathrm{C}, \mathrm{N})$-based cermets developed by a mechanically induced self-sustaining reaction, International Journal of Refractory Metals and Hard Materials, 31 (2012) 39-46.

[42] E. Chicardi, F.J. Gotor, V. Medri, S. Guicciardi, S. Lascano, J.M. Córdoba, Hotpressing of $(\mathrm{Ti}, \mathrm{Mt})(\mathrm{C}, \mathrm{N})-\mathrm{Co}-\mathrm{Mo} 2 \mathrm{C}(\mathrm{Mt}=\mathrm{Ta}, \mathrm{Nb})$ powdered cermets synthesized by 
a mechanically induced self-sustaining reaction, Chemical Engineering Journal, 292 (2016) 51-61.

[43] M. Jõeleht, J. Pirso, K. Juhani, M. Viljus, R. Traksmaa, The influence of high energy milling and sintering parameters on reactive sintered $(\mathrm{Ti}, \mathrm{Mo}) \mathrm{C}-\mathrm{Ni}$ cermets, Journal of Alloys and Compounds, 636 (2015) 381-386.

[44] L. Takacs, Self-sustaining reactions induced by ball milling, Progress in Materials Science, 47 (2002) 355-414.

[45] J.M. Córdoba, M.J. Sayagués, M.D. Alcalá, F.J. Gotor, Monophasic TiyNb1 YCxN1 - x nanopowders obtained at room temperature by MSR, Journal of Materials Chemistry, 17 (2007) 650-653.

[46] C. Suryanarayana, Mechanical alloying and milling, Progress in Materials Science, 46 (2001) 1-184.

[47] N. Burgio, A. Iasonna, M. Magini, S. Martelli, F. Padella, Mechanical alloying of the Fe-Zr system - correlation between input energy and end-products, Nuovo Cimento Della Societa Italiana Di Fisica D-Condensed Matter Atomic Molecular and Chemical Physics Fluids Plasmas Biophysics, 13 (1991) 459-476.

[48] F.J. Gotor, M. Achimovicova, C. Real, P. Balaz, Influence of the milling parameters on the mechanical work intensity in planetary mills, Powder Technology, 233 (2013) 1-7.

[49] S. Rosenkranz, S. Breitung-Faes, A. Kwade, Experimental investigations and modelling of the ball motion in planetary ball mills, Powder Technol., 212 (2011) 224230.

[50] A.S. Rogachev, D.O. Moskovskikh, A.A. Nepapushev, T.A. Sviridova, S.G. Vadchenko, S.A. Rogachev, A.S. Mukasyan, Experimental investigation of milling regimes in planetary ball mill and their influence on structure and reactivity of gasless powder exothermic mixtures, Powder Technol., 274 (2015) 44-52.

[51] P.P. Chattopadhyay, I. Manna, S. Talapatra, S.K. Pabi, A mathematical analysis of milling mechanics in a planetary ball mill, Materials Chemistry and Physics, 68 (2001) $85-94$.

[52] J.E. Oghenevweta, D. Wexler, A. Calka, Early stages of phase formation before the ignition peak during mechanically induced self-propagating reactions (MSRs) of titanium and graphite, Scripta Materialia, 122 (2016) 93-97.

[53] A.I. Gusev, A.A. Rempel, A.J. Magerl, Strongly Nonstoichiometric Compounds, in: Disorder and Order in Strongly Nonstoichiometric Compounds: Transition Metal Carbides, Nitrides and Oxides, Springer Berlin Heidelberg, Berlin, Heidelberg, 2001, pp. 43-112. 


\section{FIGURE CAPTIONS.}

Figure 1. Ignition time $\left(\mathrm{t}_{\mathrm{ig}}\right)$ of the MSR process as a function of the spinning rate. The dependence can be fit to a potential function with the following general expression: $y=$ $a \cdot x^{-b}$

Figure 2. a) X-ray powder diffraction patterns of the RPM200, RPM300, RPM400, RPM600 and RPM800 samples immediately after ignition without any post-milling treatment. b) X-ray powder diffraction diagrams of the same samples in the $34^{\circ}-44^{\circ} 2 \theta$ region where the (111) and (200) reflections of the carbonitride solid solution should appear. $(\bullet)(\mathrm{Ti}, \mathrm{Ta}, \mathrm{Nb})(\mathrm{C}, \mathrm{N}) \_\mathrm{A}(\mathrm{Fm}-3 \mathrm{~m}),(\bullet)(\mathrm{Ti}, \mathrm{Ta}, \mathrm{Nb})(\mathrm{C}, \mathrm{N}) \_\mathrm{B}(\mathrm{Fm}-3 \mathrm{~m}),(\bullet)(\mathrm{Ta}$, $\mathrm{Nb})(\mathrm{C}, \mathrm{N})(\mathrm{Fm}-3 \mathrm{~m}),(\boldsymbol{\vee})$ Unreacted Ti (P63/mmc), (ロ) Ta-Nb alloy (Im3m).

Figure 3. Observed (red dotted line), calculated (black solid line) and difference (bottom solid blue line) XRD patterns for the RPM800 sample as an example result of the Rietveld refinement analysis.

Figure 4. Quantification of existing phases in the RPM200, RPM300, RPM400, RPM600 and RPM800 samples determined by Rietveld analysis. The results are plotted as a function of the spinning rate employed for each sample.

Figure 5. Low magnification SEM images for the RPM200, RPM300, RPM400, RPM600 and RPM800 samples show their morphology and particle size. Large particles with a sintered aspect are marked with a dotted square in the RPM800 sample, which indicates the formation of a transient liquid phase.

Figure 6. High-magnification SEM images for the RPM200, RPM300, RPM400, RPM600 and RPM800 samples show ceramic particles with a sintering aspect, revealing the formation of a liquid phase during the MSR process. Different contrasts 
are observed in the RPM600 and RPM800 samples due to inhomogeneous spatial distribution of the elements.

Figure 7. Characteristic XEDS-SEM mappings for the RPM300, RPM400, RPM600 and RPM800 samples, revealing the spatial distribution of the elements. Ti: Red; $\mathrm{Nb}$ : Green; Ta: Purple.

Figure 8. a) Comparison of the XRD patterns of the original RPM600 sample (obtained just after ignition) and the same sample after being milling one extra hour after ignition. b) X-ray powder diffraction diagrams of the same samples in the $34^{\circ}-44^{\circ} 2 \theta$ region where the (111) and (200) reflections of the carbonitride solid solution should appear. 
Table 1. Milling spinning rate conditions $(\mathrm{rpm})$ and ignition time $\left(\mathrm{t}_{\mathrm{ig}}\right)$ of the MSR process.

\begin{tabular}{|c|c|c|}
\hline Sample & $\begin{array}{c}\text { spinning rate } \\
(\mathbf{r p m})\end{array}$ & $\begin{array}{c}\text { ignition time, } \mathbf{t}_{\mathrm{ig}} \\
(\mathbf{m i n})\end{array}$ \\
\hline RPM200 & 200 & 4200 \\
\hline RPM300 & 300 & 574 \\
\hline RPM400 & 400 & 171 \\
\hline RPM600 & 600 & 40 \\
\hline RPM800 & 800 & 15 \\
\hline
\end{tabular}


Table 2. Weight percentage of phases in the RPM200, RPM300, RPM400, RPM600 and RPM800 samples determined by Rietveld analysis. The R parameters, which indicate the goodness of fit, are also included.

\begin{tabular}{|c|c|c|c|c|c|}
\hline \multirow{2}{*}{ Phase } & \multicolumn{5}{|c|}{ Sample } \\
\cline { 2 - 6 } & RPM200 & RPM300 & RPM400 & RPM600 & RPM800 \\
\hline $\mathrm{Ti}$ & 0 & 0 & 2 & 2.7 & 4.2 \\
\hline Ta-Nb alloy & 0 & 0.5 & 4 & 4.7 & 6.3 \\
\hline$(\mathrm{Ta}, \mathrm{Nb})(\mathrm{C}, \mathrm{N})$ & $1.2^{*}$ & $2.7^{*}$ & 13.3 & 17.7 & 19.2 \\
\hline$(\mathrm{Ti}, \mathrm{Ta}, \mathrm{Nb})(\mathrm{C}, \mathrm{N}) \_\mathrm{A}$ & 98.8 & 96.8 & 59.1 & 48.8 & 42.1 \\
\hline$(\mathrm{Ti}, \mathrm{Ta}, \mathrm{Nb})(\mathrm{C}, \mathrm{N}) \_\mathrm{B}$ & 0 & 0 & 21.6 & 26.1 & 28.2 \\
\hline R Rietveld parameters & RPM200 & RPM300 & RPM400 & RPM600 & RPM800 \\
\hline $\mathrm{R}_{\text {exp }}$ & 3.81 & 4.41 & 4.25 & 4.33 & 4.08 \\
\hline $\mathrm{R}_{\mathrm{wp}}$ & 5.31 & 7.07 & 6.13 & 6.36 & 7.17 \\
\hline
\end{tabular}

* Not observed in the corresponding XRD pattern. 
Table 3. Lattice parameters of all existing phases in the RPM200, RPM300, RPM400,

RPM600 and RPM800 samples determined by Rietveld analysis.

\begin{tabular}{|c|c|c|c|c|c|}
\hline \multirow{2}{*}{ Phase } & \multicolumn{5}{|c|}{ Sample } \\
\cline { 2 - 6 } & RPM200 & RPM300 & RPM400 & RPM600 & RPM800 \\
\hline Ti & - & - & $\mathrm{a}, \mathrm{b}=2.961(9)$ & $\mathrm{a}, \mathrm{b}=2.961(7)$ & $\mathrm{a}, \mathrm{b}=2.962(1)$ \\
& & & $\mathrm{c}=4.651(9)$ & $\mathrm{c}=4.651(9)$ & $\mathrm{c}=4.651(9)$ \\
\hline Ta-Nb alloy & - & - & $3.306(1)$ & $3.308(2)$ & $3.308(4)$ \\
\hline$(\mathrm{Ta}, \mathrm{Nb})(\mathrm{C}, \mathrm{N})$ & $4,406(3)^{*}$ & $4.404(7)^{*}$ & $4.429(9)$ & $4.430(1)$ & $4.434(0)$ \\
\hline$(\mathrm{Ti}, \mathrm{Ta}, \mathrm{Nb})(\mathrm{C}, \mathrm{N}) \_\mathrm{A}$ & $4.312(6)$ & $4.313(9)$ & $4.316(3)$ & $4.318(2)$ & $4.316(0)$ \\
\hline$(\mathrm{Ti}, \mathrm{Ta}, \mathrm{Nb})(\mathrm{C}, \mathrm{N}) \_\mathrm{B}$ & - & - & $4.287(2)$ & $4.283(6)$ & $4.277(3)$ \\
\hline
\end{tabular}

* Not observed in the corresponding XRD pattern. 
Table 4. Crystalline Domain size (D) and microstrains (e), determined by Rietveld analysis, for all carbonitride solid solution phases synthesized in the RPM200, RPM300, RPM400, RPM600 and RPM800 samples.

\begin{tabular}{|c|c|c|c|c|c|c|c|c|c|c|}
\hline \multirow{3}{*}{ Phase } & \multicolumn{10}{|c|}{ Sample } \\
\hline & \multicolumn{2}{|c|}{ RPM200 } & \multicolumn{2}{|c|}{ RPM300 } & \multicolumn{2}{|c|}{ RPM400 } & \multicolumn{2}{|c|}{ RPM600 } & \multicolumn{2}{|c|}{ RPM800 } \\
\hline & $\begin{array}{c}\text { D } \\
(\mathbf{n m})\end{array}$ & $\begin{array}{c}\text { e } \\
(\%)\end{array}$ & $\begin{array}{c}\text { D } \\
(\mathrm{nm})\end{array}$ & $\begin{array}{c}\mathrm{e} \\
(\%)\end{array}$ & $\begin{array}{c}\text { D } \\
(\mathrm{nm})\end{array}$ & $\begin{array}{c}\mathrm{e} \\
(\%)\end{array}$ & $\begin{array}{c}\text { D } \\
(\mathrm{nm})\end{array}$ & $\begin{array}{c}\text { e } \\
(\%)\end{array}$ & $\begin{array}{c}\text { D } \\
(\mathrm{nm})\end{array}$ & $\begin{array}{c}\mathrm{e} \\
(\%)\end{array}$ \\
\hline$(\mathrm{Ta}, \mathrm{Nb})(\mathrm{C}, \mathrm{N})$ & 17 & 0.69 & 19 & 0.77 & 24 & 0.83 & 27 & 0.68 & 20 & 0.40 \\
\hline$(\mathrm{Ti}, \mathrm{Ta}, \mathrm{Nb})(\mathrm{C}, \mathrm{N}) \_\mathrm{A}$ & 25 & 0.47 & 28 & 0.52 & 29 & 0.40 & 25 & 0.47 & 28 & 0.41 \\
\hline$(\mathrm{Ti}, \mathrm{Ta}, \mathrm{Nb})(\mathrm{C}, \mathrm{N}) \_\mathrm{B}$ & - & - & - & - & 36 & 0.33 & 46 & 2.5 & 44 & 0.28 \\
\hline
\end{tabular}


Table 5. Ti, Ta and $\mathrm{Nb}$ contents for $(\mathrm{Ti}, \mathrm{Ta}, \mathrm{Nb})(\mathrm{C}, \mathrm{N}) \_\mathrm{A}$, (Ti,Ta,Nb)(C,N)_B and $(\mathrm{Ta}, \mathrm{Nb})(\mathrm{C}, \mathrm{N})$ ceramic phases determined by semiquantitative XEDS-SEM point analysis as well as the $\mathrm{C}$ and $\mathrm{N}$ absolute weight percentages, which were obtained by elemental analysis.

\begin{tabular}{|c|c|c|c|c|c|c|c|c|c|c|}
\hline \multirow{2}{*}{ Sample } & \multicolumn{3}{|c|}{$\begin{array}{c}\text { Major } \\
\text { (Ti,Ta,Nb)(C,N)_A }\end{array}$} & \multicolumn{2}{c|}{$\begin{array}{c}\text { Minor } \\
\text { (Ti,Ta,No)(C,N)_B }\end{array}$} & \multicolumn{2}{c|}{ (Ta,Nb)(C,N) } & $\begin{array}{c}\text { C } \\
\text { (wt. \%) }\end{array}$ & $\begin{array}{c}\text { N } \\
\text { (wt. \%) }\end{array}$ \\
\cline { 2 - 11 } & $\mathrm{Ti}$ & $\mathrm{Ta}$ & $\mathrm{Nb}$ & $\mathrm{Ti}$ & $\mathrm{Ta}$ & $\mathrm{Nb}$ & $\mathrm{Ta}$ & $\mathrm{Nb}$ & & \\
\hline RPM200 & $81 \pm 4$ & $10 \pm 5$ & $9 \pm 3$ & - & - & - & $*$ & $*$ & $8.2 \pm 0.1$ & $5.3 \pm 0.1$ \\
\hline RPM300 & $82 \pm 2$ & $8 \pm 3$ & $10 \pm 2$ & - & - & - & $*$ & $*$ & $8.3 \pm 0.1$ & $5.6 \pm 0.1$ \\
\hline RPM400 & $81 \pm 2$ & $9 \pm 4$ & $10 \pm 3$ & $88 \pm 3$ & $6 \pm 1$ & $6 \pm 3$ & $*$ & $*$ & $8.2 \pm 0.1$ & $5.5 \pm 0.1$ \\
\hline RPM600 & $84 \pm 2$ & $8 \pm 3$ & $8 \pm 2$ & $93 \pm 2$ & $4 \pm 1$ & $3 \pm 2$ & $36 \pm 6$ & $64 \pm 4$ & $8.2 \pm 0.1$ & $5.1 \pm 0.1$ \\
\hline RPM800 & $85 \pm 5$ & $8 \pm 4$ & $7 \pm 3$ & $96 \pm 2$ & $2 \pm 1$ & $2 \pm 1$ & $46 \pm 5$ & $54 \pm 6$ & $8.2 \pm 0.1$ & $5.1 \pm 0.1$ \\
\hline
\end{tabular}

* Detection and quantification by SEM was not possible. 


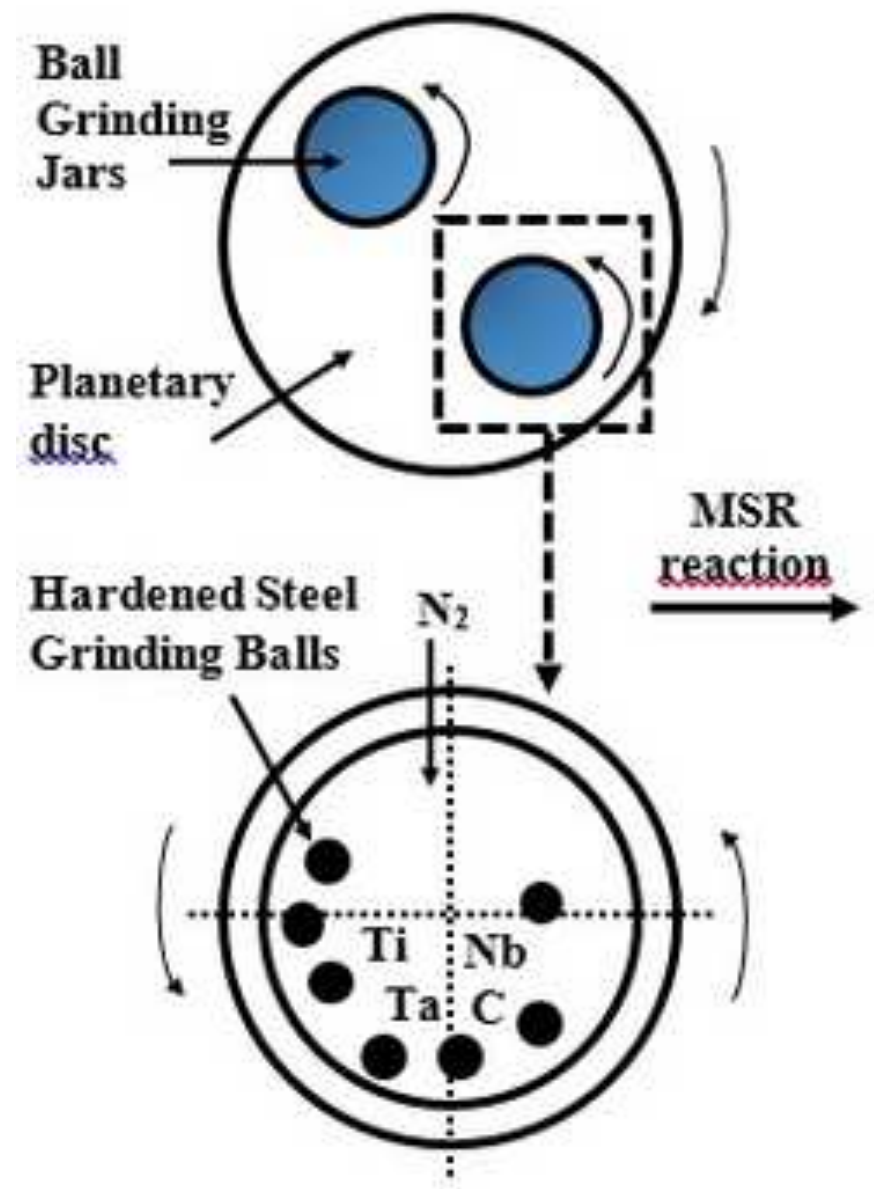

Planetary Ball Mill Reactor
High milling spinning rate

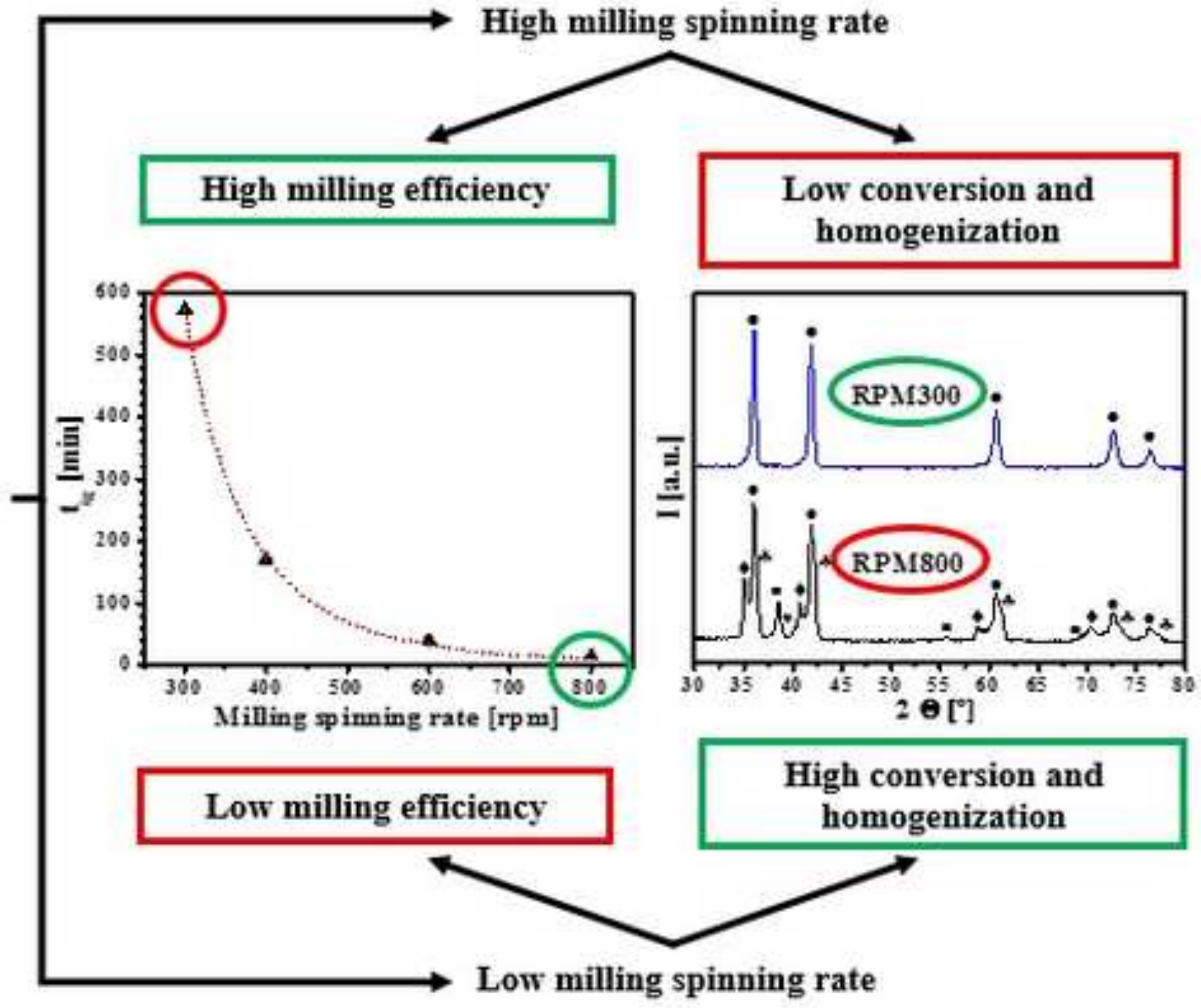




\section{Highlights}

- A $(\mathrm{Ti}, \mathrm{Ta}, \mathrm{Nb})(\mathrm{C}, \mathrm{N})$ carbonitride was synthesised in a planetary mill by MSR reaction.

- This complex quinary system could be obtained as a complete solid solution.

- The ignition time $\left(\mathrm{t}_{\mathrm{ig}}\right)$ followed a potential function with the spinning rate.

- The $\mathrm{t}_{\mathrm{ig}}$ was shortened when the spinning rate of the planetary mill was increased.

- A complete conversion and a single phase was reached at the lowest spinning rates. 


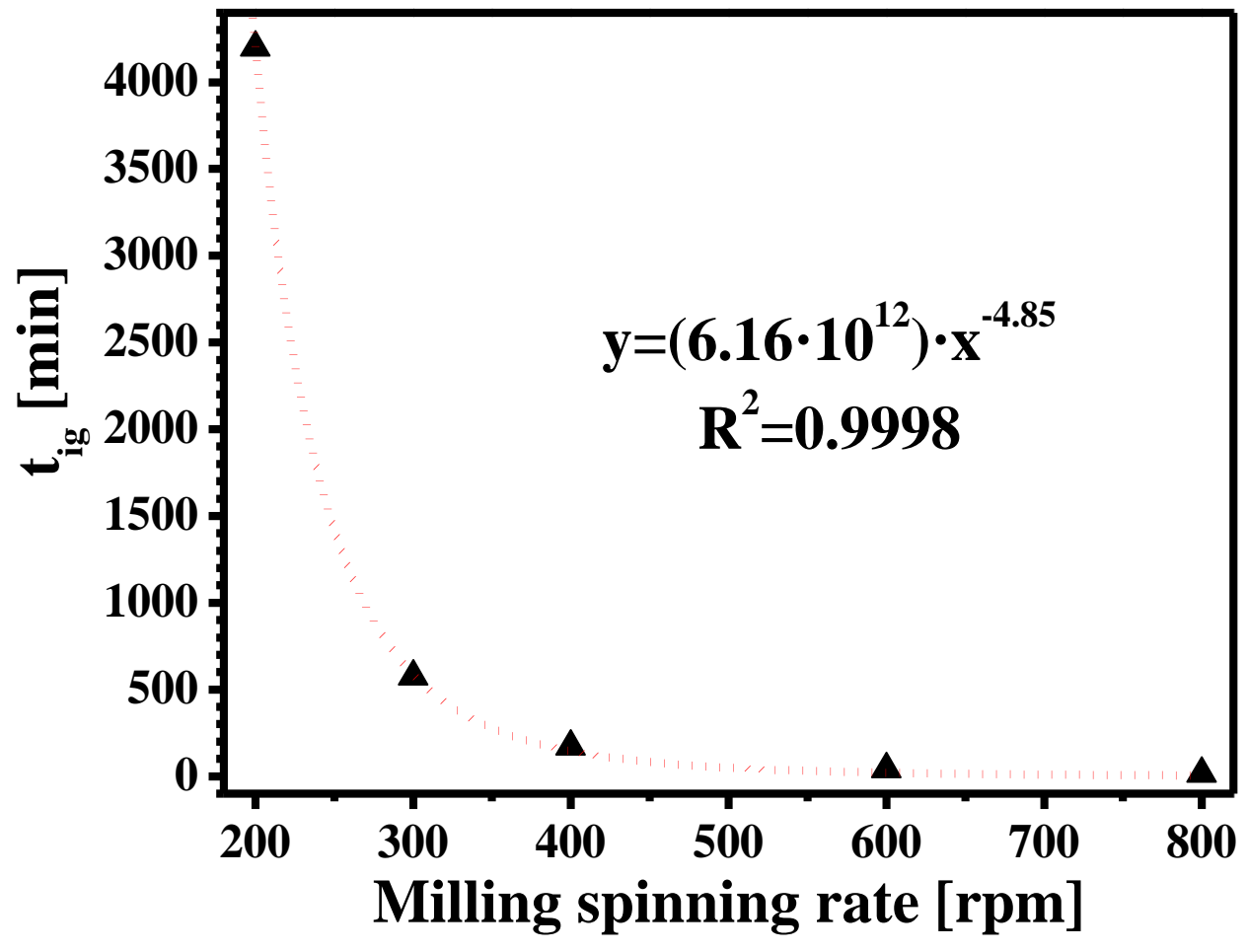

Figure 1 

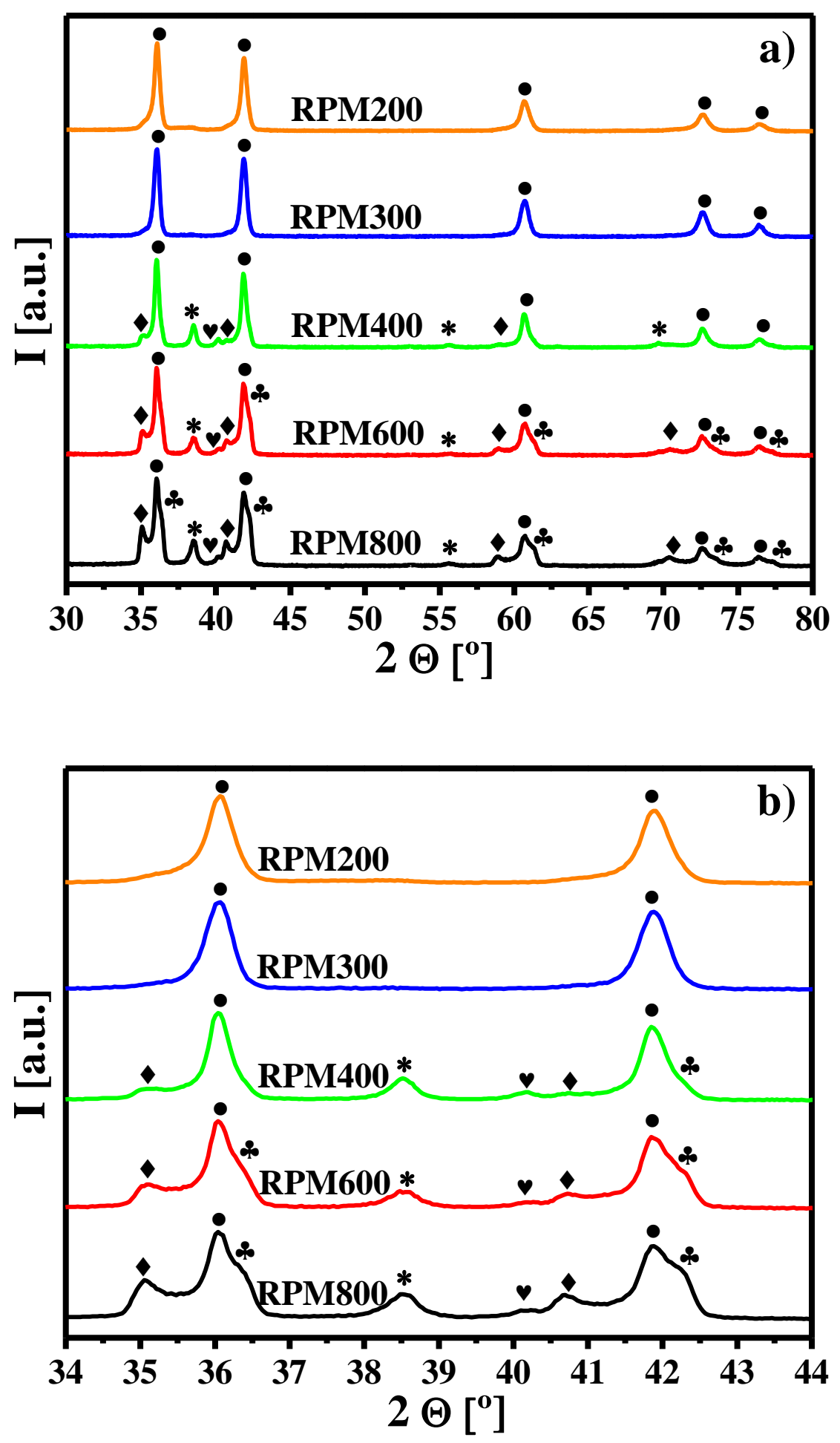

Figure 2 
Figure 3

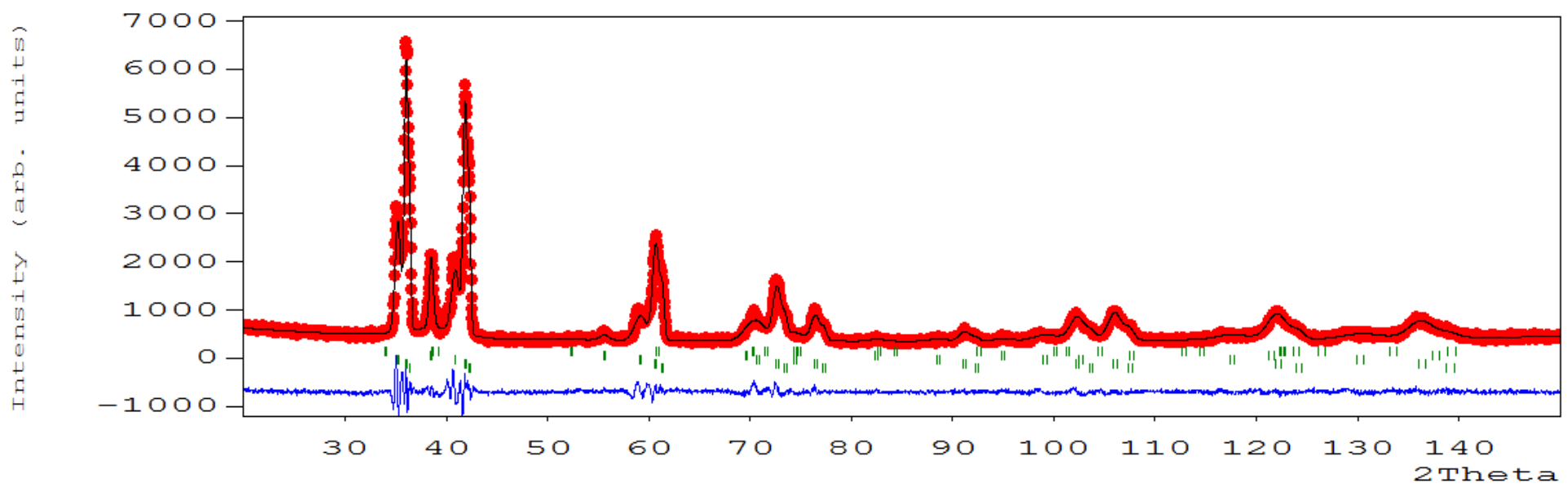

Figure 3 


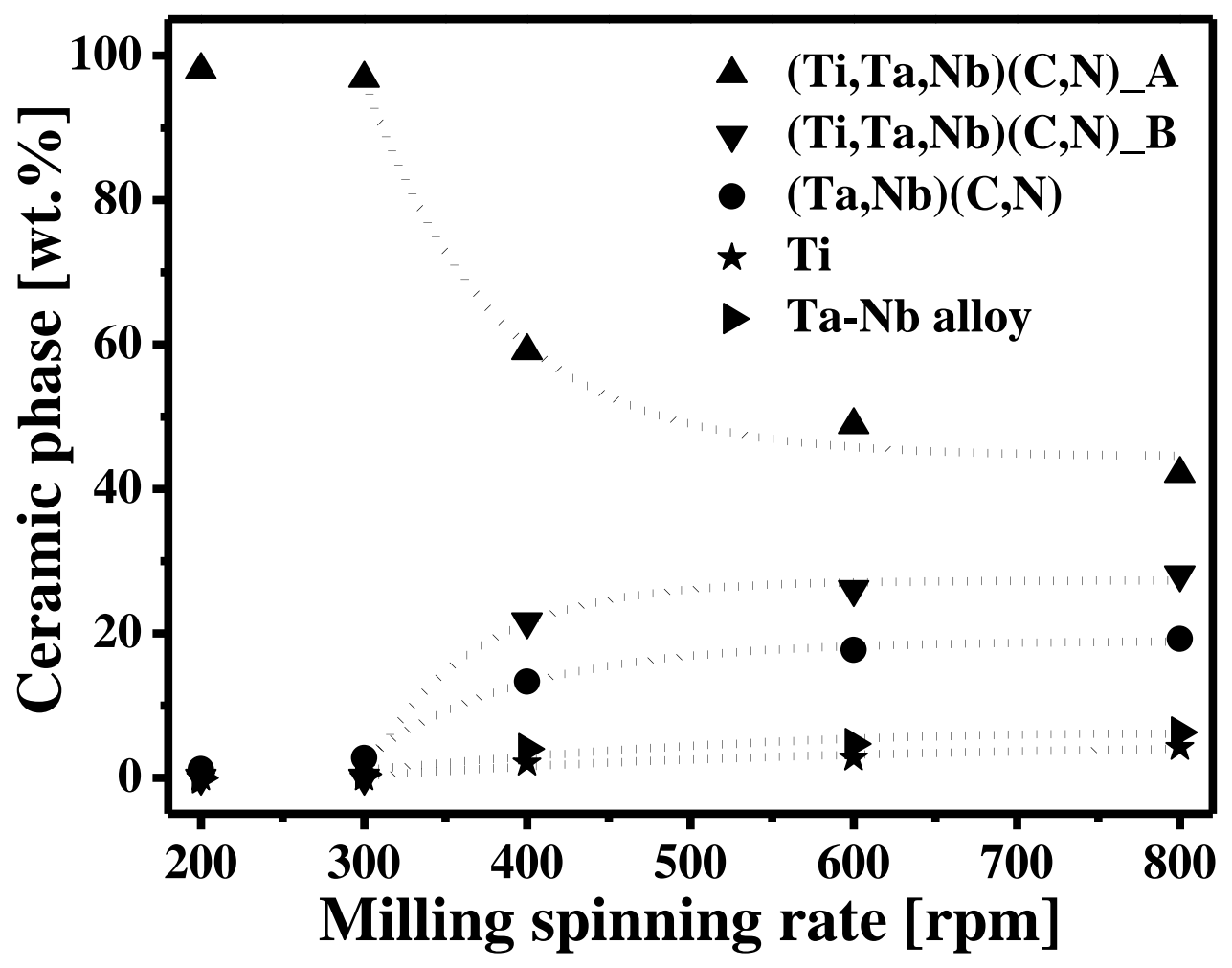

Figure 4 

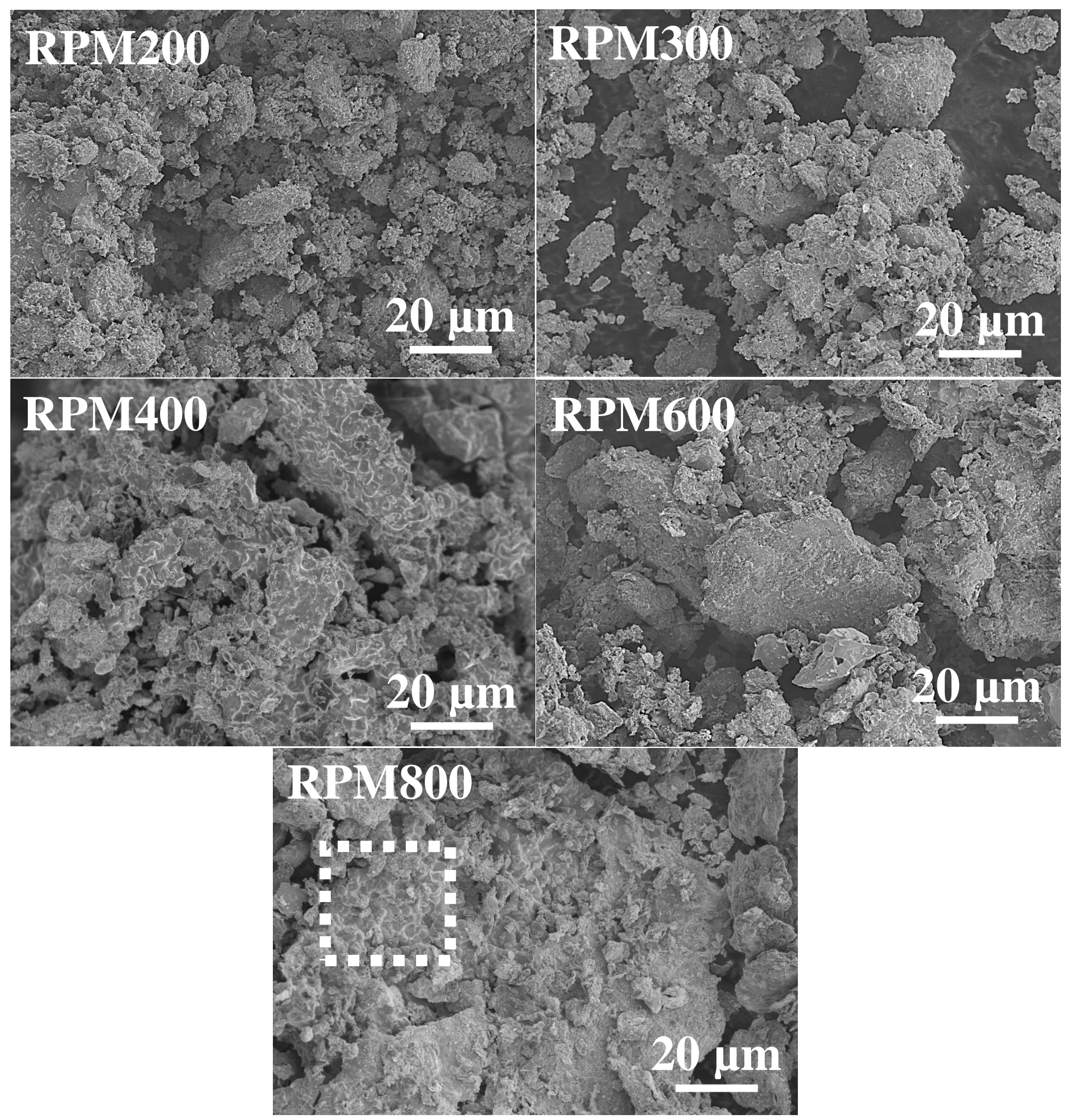

Figure 5

Figure 5 


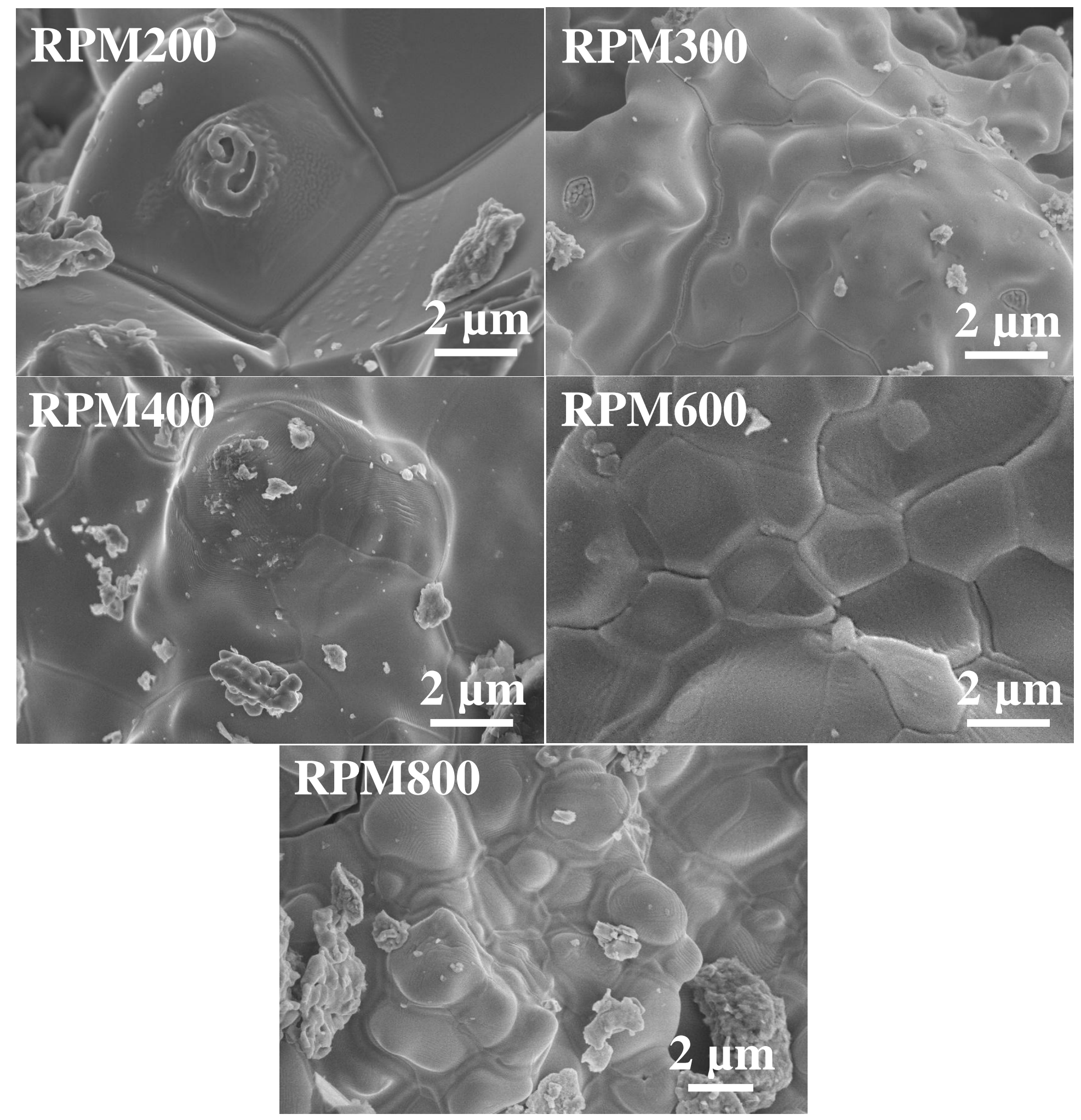

Figure 6 


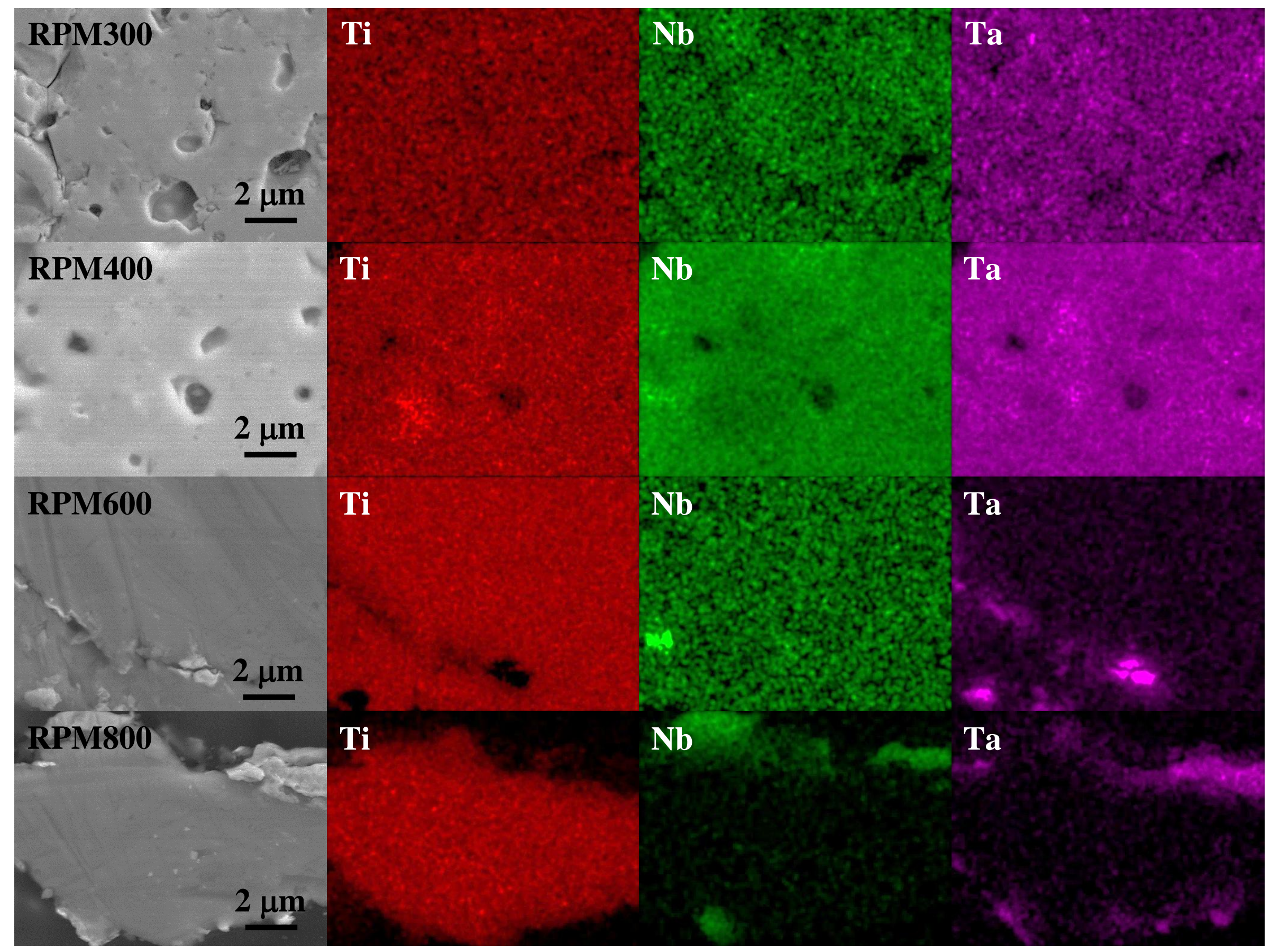

Figure 7 

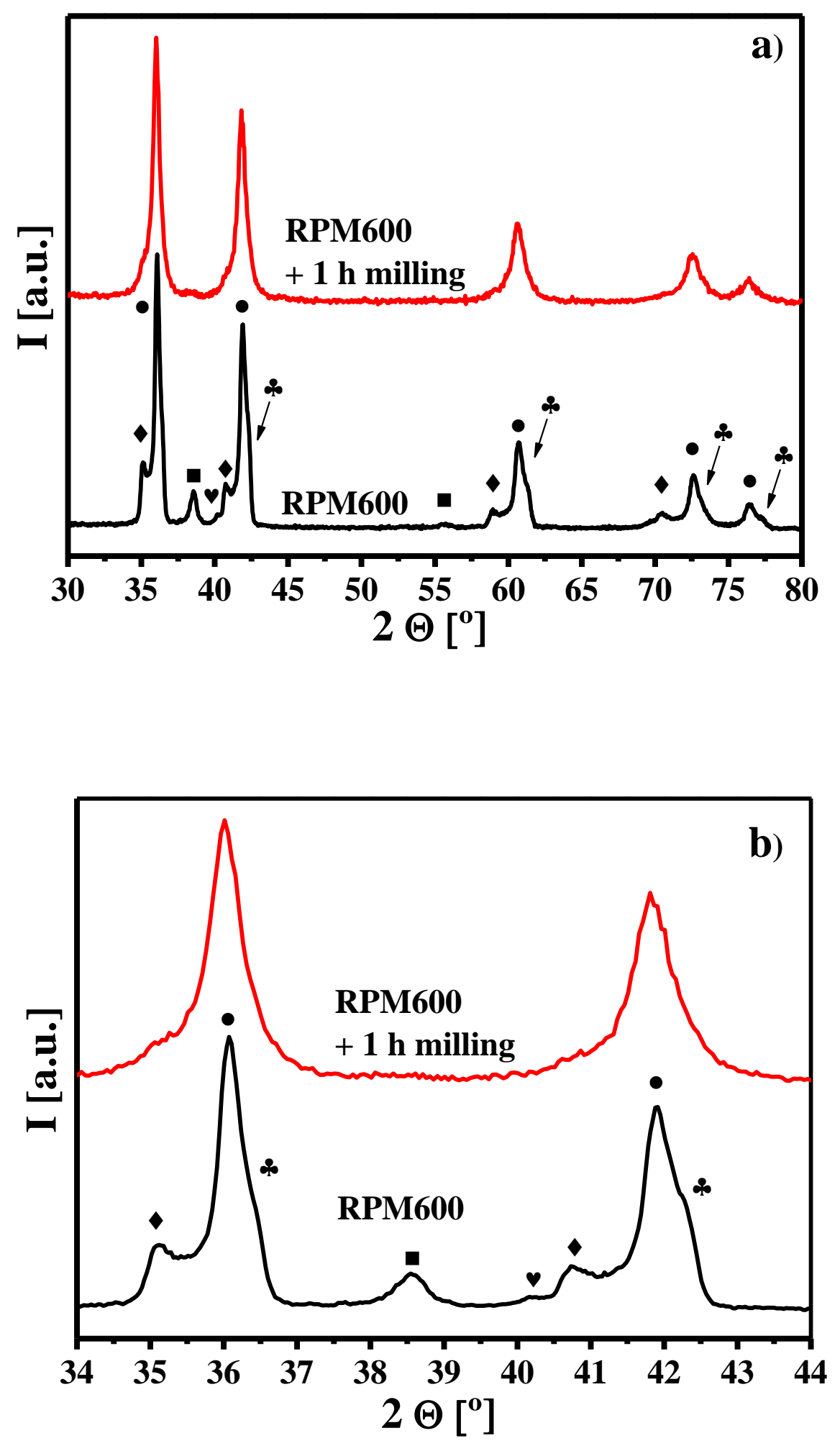

Figure 8 